\title{
Timeline interviews: A tool for conducting life history research
}

\author{
Hanne Kirstine Adriansen
}

\begin{abstract}
The aim of this paper is to explain and discuss timeline interviews as a method for doing life history research. It is a 'how to' article explaining the strengths and weaknesses of using a timeline when conducting qualitative interviews. The method allows the interviewee to participate in the reporting of the interview which may give raise to ownership and sharing of the analytical power in the interview situation. Exactly for this reason, it may not be the most appropriate method for interviewing elites or for conducting insider interviews where positionality can be at play. The use of the timeline should not lead the interviewer or the interviewee to assume linearity and coherence; it is an organising principle for the events. It provides an opportunity for linking the story with the wider social, political and environmental context during the interview. While the method is very suitable for life story research, it can also be used for other types of studies where interviews are made.
\end{abstract}

Keywords: interview; timeline; life history research; narratives; learning journey

Please cite this article as:

Adriansen, H.K. (2012). Timeline interviews: A tool for conducting life history research. Qualitative Studies, 3(1): 40-55.

\section{Prelude - the story of this paper}

My first encounter with life history research was during my Ph.D. study. This concerned a multi-method study of nomadic mobility in Senegal. One method stood out as yielding the most interesting and indepth data: life story interviews using a timeline. I conducted interviews with the head of the nomadic households and during these I came to understand the use of mobility in a complex context of continuity and change, identity and belonging in the Fulani community.

Timeline interviews became one of my favourite tools in the years to follow, a tool used both for my research in various settings across cultures and disciplines and for my work as a management consultant. Naturally, I would include the tool for my students in educational psychology when I began teaching a course on qualitative interviews in spring 2010.

Large was my surprise when I failed to find any references to the specific timeline tool. I wondered where I had first read about this type of interview and looked through my old books on development research. While I was sure the inspiration came from Britha Mikkelsen's Methods for Development Work and Research, the book did not provide any instruction on the use of a timeline for making life story interviews. I decided that the lack of authoritative literature should not omit me from teaching my students how to make a timeline interview. After an introduction, they had to use the tool for interviewing each other on their learning journey to university. The results were quite powerful. The students made in-depth interviews with each other, experiencing how an interview can be a coconstruction, as they had read in Steinar Kvale's InterViews. Afterwards, many chose to use the tool for their exam. This was a 'reflection essay' written after they had conducted an interview. Some of these essays contained beautiful reflections on the analytical power at play in a timeline interview. Unfortunately, the students could not refer to any literature related directly to the method. Reading these I decided it was about time I wrote a paper on the use of a timeline in qualitative interviews. 
I first presented the paper at a conference on life history research in November 2010. My main purpose was to establish whether the paper should be placed in the context of life history research. The valuable comments from the other participants convinced me that timeline interviews can be a useful tool for life history research. Moreover, the participants agreed that literature on how to conduct a timeline interview was missing. Consequently, I decided to place the paper in the context of life history research. I finalised the paper while teaching the course on qualitative interviews in 2011 and decided to invite my students in as co-researchers. Therefore their voice can be heard in this paper.

\section{Introduction}

Timeline or lifeline ${ }^{1}$ interviews can be used for a number of different purposes. In this paper, however, I will focus on the use of timeline interviews for life history research. The paper is written against the backdrop that there is a gap in the literature on 'how to' do timeline interviews. ${ }^{2}$ Many researchers write that they have used a timeline, but there is very little explanation of what this entails. Hence, the purpose of this paper is to describe how to conduct a timeline interview and analyse the implications of this tool for the outcome of the interview. The intention is that readers should end up with a level of understanding that enables them to analyse whether a timeline interview is an appropriate tool for their research, and, if so, feel sufficiently confident to conduct their own timeline interviews. In order to do so, the remainder of the paper is organised as follows: After an introduction to life history research, timeline interviews are carefully described including learning journey interview, how to analyse, and ethical issues. Then, two important aspects of timeline interviews are analysed namely ownership and the analytical power of the researcher. Subsequently, it is analysed how a piece of paper functions as a means for visualisation. In the following section, strengths and weaknesses of timeline interviews are discussed. Finally there is a discussion and some concluding remarks. As the paper is based on my own experiences with this method, there are examples from my research ${ }^{3}$ illustrating the practical implications of doing timeline interviews and quotes from my students who have tried the technique.

\section{On life history research}

Life history research has had a long history going 'in and out of fashion' since Thomas and Znaniecki published their The Polish peasant in Europe and America some 90 years ago (Thomas and Znaniecki, 1918-20). Meanwhile, what constitutes life history and life story has been an issue of debate. According to Goodson and Sikes (2001), a life story is concerned with understanding a person's view and account of their life, the story they tell about their life (2001: 87). In life history research, the intention is to understand how the patterns of different life stories can be related to their wider historical, social, environmental, and political context. Yet,

\footnotetext{
${ }^{1}$ In the literature both timelines and lifelines are mentioned. I see timelines as an overarching concept including lifelines. Subsequently, I use the concept timeline in this paper.

2 The use of timeline interviews outside qualitative research interviewing is not uncommon. In the mid 1990s there were many studies especially in psychology using the so-called time-line follow-back (TLFB) interview method as a tool for helping people with addictive behaviours (e.g. Brown et al., 1998; Carey, 1997). However, these are not qualitative studies and the use of a timeline per se does not render them relevant for this paper.

${ }^{3}$ My own philosophical stance is predominantly within critical realism and therefore the examples of my application of the timeline in interview research will be marked by this stance. My hope is, however, that the article can be of some inspiration to others doing qualitative interviewing irrespective of their philosophical stance and modified to the purpose of their research.
} 
Rosenthal (1993) uses life history to denote the 'lived through life', while the life story denotes the narrated life. In this paper, I use the former understanding of the concepts. One may notice that there is little difference between different researchers' understanding of life story (a narration), but life history has different connotation relating to the purpose of research. While Goodson and Sikes (and others) are interested in seeing life stories in relation to the wider societal context, Rosenthal and e.g. Bar-On (2006) are concerned with understanding the way the story is told. Plummer (2005) points to the different goals of life (hi-)story research within different disciplines and how this goal affects issues of validity. Hence, difference in purpose has implications not only for how the analysis is performed, but also for the way interviews are conducted.

Particularly in sociology, life story interview has been taught as a method for capturing people's own perceptions of their lives (Goodson and Sikes, 2001). In development studies and human geography, which is my background, life history research is linked to 'oral history' projects aiming to explore the culture and history of certain places through the memories and recollections of its people - in their language, using their vocabulary (e.g. Cross and Barker, 1994). Especially people's perceptions of change have been subject to study by human geographers and anthropologist alike. This was my entry into the field. By making life story interviews with Fulani nomads, I gained insights that I had not gained by using other methods - structured interviews, questionnaires, observations. ${ }^{4}$ I came to understand the life world of the interviewee in a new way. A life world that was so different from my own that I assumed the power of the method was related to these differences. Little did I know that the method was equally useful for studying people leading lives very similar to my own.

Some life history researchers are predominantly interested in the way stories are told and less interested in the relationship between the story and the lived life (Plummer, 2005). When we focus on the stories we tell ourselves about who we are, then the way we tell the story is very important - what is told and what is not being told (Goodson, 2010). In this case, it becomes important for the interviewer to be silent, not to take over the interview with too many questions or a set frame for asking questions (Rosenthal, 1993). When, on the other hand, the lived life also becomes important, when we want to relate a person's life story to his/hers actions, then 'facts' 5 become important. It is not only how the story is told, which is relevant, it is also how the story relates to what has happened in the interviewee's life and how the person has reacted towards it. Hence, both the story and the lived life become important. Timeline interviews as described below can be used by researchers who are interested in the lived lives of the interviewees and may be less relevant for those who are interested in the way stories are told.

\footnotetext{
${ }^{4}$ My Ph.D. project concerned the mobility patterns of Fulani nomads in Senegal. I used a wide range of methods and data sources from GPS and satellite imagery, over questionnaires, to qualitative interview (including timeline interviews) and participatory observations. Fieldwork was conducted on several occasions from 1997 to 2000. Eight timeline interviews were made lasting about two hours each. An interpreter was used for translating from the local language, Pulaar, into French. As the nomads were illiterate, they did not participate in writing on the timeline (Adriansen, 2002; 2008).

${ }^{5}$ I use the word 'facts' for lack of a better word and use inverted commas to account for our different understandings of the word fact depending on our ontological and epistemological stances.
} 
One of the strengths of life story interviews is the strong emphasis on holism. Lives are seen as whole, the public and private cannot be separated, and lives are contextual and should be studied and understood this way (Callewaert, 2007; Goodson and Sikes, 2001). The timeline method increases our possibilities of seeing events and perceptions of these events within contexts of wider life experiences. Often when people tell their story, it is nice and linear, rational and coherent - it becomes 'one' life. But we live many lives and by using the timeline method explained below, we can make room for these different lives, for the different stories and their contexts. However, the timeline should not be seen as an assumption of linearity of a chronological timeline. It is a tool to provide a visual representation of main events in a person's life and for engaging the interviewee in constructing this story. Goodson and Sikes (2001) argue that timelines can be a useful start for life history research, for instance by inviting the interviewee to construct a timeline of key events. My approach to the use of timelines is somewhat different. When I conduct a timeline interview, the construction of events along the timeline is the basis for the whole interview. Hence, it is not merely a tool for starting an interview. The construction of the timeline is a collaborative effort shared by the interviewer and the interviewee. I do not consider the timeline interview to be the sole source of information for life history research. But it is a useful tool for collecting and constructing for life stories.

\section{How to conduct a timeline interview}

The tool itself is not complicated to handle, but, as with other interview techniques, it takes time to master. The basic ingredients are a large piece of paper and a number of coloured pens. The interview may be taped (and transcribed); it depends on the type of analysis intended and on how the use of a tape recorder may affect the interviewee. The use of tape recorder for qualitative interviews is an issue in itself, which I will not address further in this paper (see e.g. Kvale, 1996).

The backbone of the method is the drawing of a timeline in the middle of the paper. I usually draw it horizontally, but it could be any other way the interviewee prefers. Ordering of events can be guiding the interview. An important issue is when the timeline should begin and end. In the case of the nomads from Senegal, the timeline began with their year of birth and ended with the year of the interview - the end of the story so far. It could also begin when the interviewee's parents met or any other significant event prior to the birth of the interviewee. Likewise, the timeline could also continue into the future if the interviewee finds this relevant for the story.

Depending on the type of life story we want the interviewee to tell, the interviewer can open with different questions. When interviewing the nomads, I asked about the important events in life. These turned out to be when they received their first animals (as kids 5-7 years old), when they married, had children, were divorced and so forth. I marked these events with different colours and lines parallel to the timeline. By asking about important events first, we can take time to explore when and how these events unfold, how and if they are related and affect each other. The paper is a physical layout which permits different lines representing different perspectives; these may be the 'core' of the story, e.g. the home/family/private in the middle and work/outside towards the edges. Usually, the interviewee begins with the most important events, which we will note on one side of the timeline and gradually 'outside' events that have affected the events may come up as the story unfolds and be noted on the other side of the line. When trying to place events in order, the interviewee sometimes realise that these events took place in a different order from what the person initially remembered. This may mean that they de- and re-construct their story; they see different patterns of 'cause and effect'. In this way, the 
paper and the drawings along the timeline become important visual tools for seeing how the story is told. It is also used for attending to the tensions and contradictions in the story as these become more apparent when they story is laid out on the paper in front of the interviewer and the interviewee. Likewise, the researcher may challenge the interviewee's interpretation of 'cause and effect' if these seem very 'neat' and one-dimensional.

Often, the paper is split into two by the line in the middle, but it can be divided into three or four parallel sections thereby leaving room for different stories to be constructed alongside each other. Or the different sections can be used for different contexts - the local, the national, the socio-political or the environmental - depending on what is important for understanding the story/stories. Thereby there is an emphasis on context. According to Callewaert (2007), context should always be thought of in life history research - also when the interviewee does not touch upon it him-/herself. By leaving room on the paper for context, the researcher is prompted to focus on context in the interview - or afterwards. The researcher can also choose to add information about social or political events along the timeline in the subsequent analysis. However, the interviewer should remember to add this information with another colour/in another part of the paper thereby indicating clearly which part of the paper is the life story and which part is used for the analysis. Some may find this emphasis on context premature in the life story interview and prefer to leave it to the analysis, i.e. to the life history research. I prefer, however, to include the interviewee in understanding his/her life in context. In this way, the analysis may begin in the interview situation. This is not new, though, as Goodson and Sikes (2001) have also noted, life history research is iterative and the analysis of an interview already begins in the interview situation.

The interviewee can participate in writing and drawing. After the researcher has explained the purpose of the interview and the process, he/she can encourage the interviewee to take part in writing and drawing on the paper. In this way, the interview can become a 'co-construction' which many qualitative interviews are, as Kvale (1996) has explained. The paper serves as a 'collective memory' where the story can be seen both by the interviewer and the interviewee. It is easy for both parties to return to an issue already discussed and this can be linked with other events along the way. Whether the interviewee is participating in writing or not, she/he is usually engaged in following how the story enfolds on the paper. This is quite different from an interview where the interviewer writes notes on a piece of paper that the interviewee cannot see. Using the paper as a collective memory can make the interview a collective process allowing the interviewee to take ownership of the process. This is discussed further in the following sections. In my experience, this type of interview takes time. It is by nature very explorative, which means that the end result is not known, the interesting issues may be quite different from what the interviewer expected, and the interviewee may be surprised to see unexpected links between events. Often, approximately two hours have been appropriate for the timeline interviews that I have conducted. This is enough time for stories to emerge and 'materialise', yet it is usually not so long that the interviewee gets too exhausted.

\section{Learning journey interviews}

The timeline interview can be used for capturing learning journeys. A learning journey is the learning process experienced during time. In principle, the journey can be any course or learning process at school or elsewhere. For the learning journey interview to work, the interviewee has to be able to reflect on the events and be able to relate to learning aspects. I have used learning journey interviews for a project concerning creativity in higher education. I interviewed former Master students on their learning journey during their two year programme 
in leadership and innovation (Adriansen, 2010). Also, my master students have used learning journey interviews to analyse the outcome of continuing education courses, in particular leadership courses - both in-house and external, open courses.

One student, Marcelo, decided to make the timeline vertical instead of horizontal. This small change gave raise to some other interesting changes in the construction of the learning journey: The bottom of the line, i.e. the beginning of the story, changed from being a line to being a number of intertwined lines - like roots of a tree. The simple change in the drawing of the timeline caused a slightly more complicated story to be told - a story where different events, different roots led to events along the main story line, the tree trunk. Likewise some of the interviewees saw different perspectives for the future, i.e. different lines emerging from the trunk like the crown of a tree. These interviews were made with a group of people who had finished a leadership training course based on 'Theory U' (Scharmer, 2007), a course with a spiritual orientation focusing very much on emergence, presence, and 'leading from the future' (Scharmer, 2007). The interviewees were academics, who were very reflective and capable of expressing themselves. They took part in developing the interview method. From the outset, Marcelo had been concerned to use an interview method that was appropriate for capturing the learning process that interviewees had experienced during the course. Marcelo found that the explorative character of the timeline method made it particularly useful for his purpose.

Marcelo argues that the learning journey interview should be seen as a rhizome rather than a tree. Marcelo is inspired by Deleuze who adopts the concept from the natural sciences and uses it as an image of thought (Deleuze in Boundas, 1993). In botany, a rhizome denotes a subterranean steam and is fundamentally different from roots of a tree. Whereas a root assumes a very definite shape for instance as a tree, the rhizome assumes very different forms. While a tree has a hierarchical structure with different layers, the rhizome has no points or positions, no centre or core: "Any point of a rhizome can be connected to anything other, and must be" (Boundas, 1993: 29). It is a multiplicity of relations, lines of development. The bulbs and tubers we see at the surface are thus manifestations of the larger network and not a result of a unique seed and thus not simply predetermined in a strict causal sense. By using the rhizome as an image of thought, Deleuze's idea is to avoid narrativizing history and culture, which is often the case when using the tree metaphor where the source of an event is easily found by tracing back to the root and the conclusion is found by looking forward towards the crown. Hence, causality is charted along the chronological line of the trunk. A rhizome, on the other hand, can be used to represent culture as a map of attractions or influences allowing for multiplicities. Similarly, the stories which are sold during the learning journey interview, Marcelo argues, should be seen as some of the many possible stories, not as the only and 'true' story about the learning journey. Hence, it should not be seen as a tree (the story being the trunk) with many ways (roots) leading to it and many possible outcomes (the branches). Instead it is but one in a number of possible sprouts from a root with no centre. The story constructed around the vertical line during the interview can be seen as one vertical line out of a number of possible lines, yet remaining part of the horizontal structure with other lines of connection and meaning, which also could be visualised. This way of interpreting the use of a timeline for an interview is based on a more poststructuralist approach than the one I have employed in this paper generally.

\section{Analysing the interviews}

The timeline interview is an interview technique or a tool for making interviews; hence there is not a certain type of analysis pertaining to timeline interviews. On the contrary, one should 
adapt the way the timeline interview is conducted to the type of analysis wanted. For instance Marcelo, mentioned above, adapted the learning journey interview to the poststructuralist stance he used in his Master thesis.

In my own research, I have used timeline interviews in different ways; however, they have never been my sole data source. In my Ph.D., I combined a number of different types of data derived from both qualitative and quantitative methods (Adriansen, 2002; Madsen and Adriansen, 2004). Usually, I make timeline interviews as part of a field study and therefore I also have observations and other types of data which can be used in combination with the interviews. How the interviews are analysed, how they are combined with other types of data, and how they are validated depends on the purpose of the study.

Within life history research, there are a number of different strategies for analysis. As mentioned above, Goodson and Sikes (2001) analyse individual life stories within a larger social, historical, and political context thereby making life history research. Bar-On (2006) has used life stories and narratives for creating dialogue between Jews and Germans, Palestinians and Israelis. For this research, he has made qualitative interviews both with groups and with individuals. Even though Bar-On does not use timelines, he uses chronology as one level of analysis in his three level strategy (2006: 33):

1. A chronological analysis (the life history). Extraction of calendar dates and events associated with a specific time or age.

2. A linguistic analysis. Differentiation between descriptions or reports (usually emotionally detached), argumentation (addressing a hidden interlocutor), and stories (which have a definite beginning and end in time and space, a drama, usually with deeper emotional involvement).

3. A sequential analysis of the biographical data, identifying the topics discussed, starting from the beginning of the interview and moving forward step by step.

Using a timeline for the interview will no doubt focus the interviewee on the chronological dimension of the narrative. Hence, if the main interest of the researcher is the narrative, 'the story as it is told' with as little interference as possible, the timeline would probably be seen as 'polluting' this story. Researchers like Bar-On (2006) and Rosenthal (1993) are very interested in capturing the narrative undisturbed. When they make biographical interviews, they ask the interviewee to tell their life story the way the interviewee wants and only ask clarifying questions afterwards. In this case, it makes more sense to leave the chronological aspect until the analysis, thereby leaving it to the researcher - for better or for worse. Finally, it should be noted that - depending on the type of analysis - a timeline interview can be more complicated to analyse due to the less verbal and more visual character (this is discussed later).

\section{Ethical issues}

As in other qualitative interviews, ethics are important in timeline interviews. What may happen - possibly due to the interviewee's feeling of ownership and the explorative nature of the interview - is that the interview becomes very personal. I have experienced this on a number of occasions and my students have reported the same. During class, where they have less than an hour to conduct a timeline interview with each other, the majority manage to create 
an atmosphere of trust where the interviewee open up, share and explore. Moreover, many of them return to class having shared deep feelings and new understandings of their lives:

I: "Even though I had told the story before, I saw new patterns by looking at the paper" R: "It was more like a conversation - with more than one person asking questions"

Yet, one of them found using a piece of paper an obstacle; perhaps because it was the first time he tried it:

I: "I was so focussed on getting something on the paper that I did not ask very much about emotions and influences"

Those who choose to work in greater depth with the method for their reflection essay usually write about the ethics involved, because this type of interview appears to enable a closer contact and more trusting atmosphere. We ascribe this to the explorative and unstructured nature of the interview without a question guide, to the use of artefacts/paper and lack of eye contact, and to the situations when the interviewee feels ownership to the process thereby wanting to explore and understand together with the interviewer. It appears that for many structuring the interview around the timeline helps creating a safe 'potential space' (Winnicott, 1988) between the interviewer and the interviewee. A student reflected: "The paper between us provided safety". Some felt that sitting next to each other with the paper in front provided a safe space.

Consequently, when conducting timeline interviews, the researcher has to be aware that the interview can become very personal and intimate. As Goodson and Sikes (2001) have mentioned, the researcher should manage to exercise caution, be emotionally sensitive and intelligent. The researcher is responsible for stopping or diverting the interview, if the interviewee is approaching issues that are too sensible. Of course this can be very difficult to judge. But being aware of this effect beforehand hopefully means that the interviewer will be aware in the interview situation and can guide the interview in an ethically manner when approaching delicate issues.

In my research, the paper with the timeline is a means of data, which has the same status as notes made during an interview. This implies that it is simply the researcher's tool which should remain in the background and not be published when presenting the results of the study. There are two main reasons for this: Firstly, the timeline would usually enable the reader to situate a life story in time and space whereby anonymity would be lost. Secondly - and this may sound like a contradiction - the timeline in itself does not tell the reader very much. The drawing and the notes along the timeline are by no means the full extent of the information derived from the interview. Just like a reader would be puzzled by looking at the researcher's notes, but might still be able to decipher personal information from interviewees. Therefore there is no reason for publishing the timeline, it might even be unethical.

\footnotetext{
${ }^{6}$ The quotes in the paper are from master students of educational psychology participating in a course on qualitative interviews. They were asked to conduct a number of interviews with each other. Towards the end of the course, they were asked to conduct a timeline interview lasting approximately half an hour. When they returned, I wrote down their comments and reflections. It should be noted that the comments were made in Danish. I have chosen verbatim translations over 'elegant' ones.
} 


\section{Ownership and analytical power}

There are two important and intertwined points, which I consider benefits of the timeline interview method. These concern ownership and analytical power. In my experience, interviewees often take ownership of the timeline interview and sometimes the analytical power is distributed in the sense that the interviewee has a share in the analytical power during the interview. I will try to explain why this happens. However, it is important to note that what takes place before and after a timeline interview is not different from other qualitative interviews; here the analytical power belongs to the researcher solely.

The large paper allows both the interviewer and the interviewee to 'report'. Hence, the interviewee can take ownership by drawing and writing, by participating in the reporting. The fact that the interviewer shares the large piece of paper with the interviewee instead of making notes on a 'private' piece of paper or in a note book means that the interviewee can see what is being noted and the paper thus becomes a collective memory. A student said: "It was nice that I could see what the interviewee wrote and left with". Sharing the notes, the memory with the interviewee may give him/her ownership to interview. He/she has the possibility to steer the interview in a certain direction, although it is still the interviewer who ultimately holds the analytical power and thereby is the one who can decide which issues are relevant for the interview.

It is easy to claim that the interviewee takes ownership, but how can this be seen? An example is that the interviewee often will ask to get a copy of the paper with the timeline illustrating the life story. The interviewee feels that the timeline (also) belongs to them. I have never experienced an interviewee asking for a copy of my notes or the audio file - that is perceived as the researcher's material. Likewise when my students return to class upon making a timeline interview, I asked them who got to keep the paper with the timeline. Most often it is the interviewee. They explain that it seem most natural as the timeline illustrated the interviewee's life.

Bar-On (2006: 26) claims that: "People who tell their own story thereby repossess it, so that it contributes to their self-esteem". Repossession is a way of taking ownership to the interview. It is this repossession which in my experience is stronger when the story told simultaneously is visualised along the timeline on the paper. One of the students expressed it this way: "Positions were levelled". This levelling may also be related to analytical power. I am inspired by Rose's (1997) use of the concept analytical power of the researcher. She explains that the researcher holds a privileged position by deciding who is a relevant interviewee, by formulating the questions asked and when they are asked, by directing the flow of the discourse, and by having the final power of interpretation. This is the analytical power of the researcher and it should not be neglected. Rose further links the analytical power of the researcher to the issue of distance. Even though the researcher and the researched may be placed in the same landscape of power, there is still a distance between them because of the analytical power of the researcher.

In 'conventional' interviews, the interviewer holds the analytical power. It is the interviewer who decides that the interviewee is a relevant person to talk to; it is the interviewer who constructs the interview guide; it is the interviewer who asks the questions (Kvale, 1996). When conducting a timeline interview, it is still the interviewer who decides that the interviewee is a relevant person to talk to and likewise it is the interviewer who decides that a timeline interview is appropriate for the interview. So far the analytical power is held by the interviewer. 
When the timeline interview starts, however, the situation is different from a 'conventional' interview because the interviewee is invited to participate in 'constructing the story'. The questions are not prepared beforehand. The key events are articulated by the interviewee and he/she can participate in linking them by writing and drawing on the paper with the timeline. In this way, the analytical power is shared, although not equally, in the interview situation. The timeline interview with its use of artefacts allows the interviewer and the interviewee to be situated closer in the landscape of power - to use the vocabulary of Rose (1997). One of the students remarked, however, that it was difficult for the interviewee to take part in writing on the paper and this meant that the analytical power was not shared in this case. It is important to note that prior to and after the interview itself, it is still the researcher who holds the analytical power solely.

In case of the Senegalese nomads the interviewees were illiterate and did therefore not participate in the reporting. Nevertheless they found the whole setup with the large piece of paper and the coloured pens entertaining. The fact that they could follow what was going on rather than me writing in my notebook out of their sight - was no doubt useful in establishing a trustful atmosphere.

\section{A piece of paper - a visualisation}

To use a piece of paper and thereby visualise the interview can benefit both the researcher and the interviewee. By using a timeline for the visualisation, we can increase our chances of seeing events and perceptions of these events in context with the wider life experiences. This perception was very pronounced among the students:

$\mathrm{R}:$ "The timeline means that it is easier to keep focus because it is on the paper"

I: "The visual made me think in outer structures"

R: "The paper means that one can go back and add more [to the story]"

I: "The visual opens the possibility to reflect out loud"

$\mathrm{R}:$ "The interviewee recalls new things and is participating in the analysis"

I: "Including the wider context gave me an 'aha' experience"

Similar experiences can be seen in Hviid's paper on children's development (2008). Hviid made interviews with 12-year old Danish children and explains that 'to lighten the task' she asked the children to draw maps of their lives on big sheets of papers. Hviid wanted to capture both a temporal and a spatial dimension, thus maps and not only timelines. During the interviews, these visualisations served as a means for further discussion and reflection. Although the children could map their lives in any way they wanted, they all chose to "present their lives on the map in chronological age, starting from their birth" (Hviid, 2008: 185).

Another interesting discussion regarding timeline interviews is the effect of the timeline. It may seem like a paradox, but by using a timeline the story often becomes less linear. It is because we can make room for different lives, for the different stories and their context along the timeline. It is also due to the fact that by visualising the interview, it is possible - both for the researcher and for the interviewee - to 'jump' in the story/interview. The visualisation along the timeline can become like a painting where you can refine different fields in any order you like, add new layers. In a 'conventional' interview, on the other hand, the interview has a tendency to become more linear because it is more controlled by words - the linearity of a story line, of a written text. 
The visualisation on the paper also affects how the interview is conducted. While some researchers (e.g. Goodson and Sikes, 2001) recommend that the interviewer keep eye contact with the interviewee, I find that it is very culturally specific what constitutes appropriate eye contact. Having conducted fieldwork and interviews in diverse cultural settings from rural Senegal over bureaucracies in the Middle East to academia in Denmark, I am used to pay attention to these differences. While eye contact can create an intimate atmosphere, it can also be intimidating. In my experience, it is sometimes easier to talk about personal issues when there is no eye contact, but an atmosphere of presence - for instance because both the interviewee and the researcher are engaged in the same activity. This could be the construction of the timeline. One student told: "The paper removes the focus from the slightly formal situation". This is similar to the atmosphere that we may experience when we are doing the dishes together and can have a confidential conversation without eye contact, or when two people are taking a walk together.

Two students commented on the timeline interview in this way: "It is a very efficient means of interview" and "It is a good explorative type of interview" and many were amazed by the amount of information they managed to get within a relative short period of time: "It provided a fast overview of the person sitting in front of $\mathrm{me}^{\prime \prime}$. In some types of life history research, piecing together a life story can seem like a jigsaw puzzle. When the researcher is visualising the life story by writing and drawing along a timeline and possibly involving the interviewee, the researcher and the interviewee can be doing a joint work where the interviewee also looks for 'missing pieces' because he/she can see something is missing. This hunt for missing pieces can cause the interviewee to tell more than in a 'conventional' interview situation, where the collective memory in shape of the visualisation of the timeline does not exist. Thereby part of the story which might have remained untold, censored or suppressed, may be told.

\section{Strengths and weaknesses of the timeline interview method}

As any other method, the timeline interview has its strengths and weaknesses - and sometimes strength can also be a weakness. While the visualisation of the interview by the use of a timeline is beneficial for both the researcher and the interviewee, the use of a timeline, however, could be seen as an assumption of linearity of a chronological timeline. This is not the intention. The timeline is merely a tool for untangling the story and for engaging the interviewee in constructing this story. Depending on the researcher's stance and research question, it may be appropriate to work with different conceptions of time, for instance 'subjective time' and 'objective time' as discussed by Hviid (2008). ${ }^{7}$ When people tell their story, it is often coherent, rational and linear. However, when trying to place events in chronological order, the interviewee sometimes discover that these events took place in a different order from what the person initially remembered. This may mean that they de- and re-construct their story; they see different patterns of relationship. In this way, the paper and the drawings along the timeline is also used for attending to the tensions and contradictions in the story as these become more apparent when they story is laid out on the paper in front of the interviewer as well as the interviewee.

I have argued that the use of artefacts, in this case paper and pens, can create ownership of the interview by the interviewee. One should be aware, however, that not all interviewees like to

\footnotetext{
7 Subjective time can be represented by 'durée' (Bergson, 1915; 1917) which is a nonchronological composition of past, present, and future. Objective time, on the other hand, is a social structure that is used for coordinating activities of members of society (Hviid, 2008).
} 
participate in this process. The first time I made timeline interviews, the interviewees could not participate as they were illiterate. Moreover, there was a language barrier. So interviewees should, of course, be literate, be confident in writing and feel secure about the process, so they know what to write. Even amongst the students, there was some reluctance to write. Yet, some found it beneficial as writing made them think of new things to add to the interview. Even when the interviewee does not participate in writing, the piece of paper can be useful, because it attracts attention. This means that it is easier to be silent and reflect. Both the researcher and the interviewer can look at the paper to create overview and think of new questions/answers. Perhaps this is why many students reported that the interviews were very calm with a pleasant pace; some mentioned a feeling of flow.

Due to the sharing of ownership and analytical power, the method may not be the most applicable for interviewing elites. When conducting interviews with powerful people high in the social hierarchy it may be useful to balance their power by maintaining one's analytical power. Likewise, timeline interviews may also be more difficult to conduct with insiders. Especially in education research it is common to have an insider position (Sikes and Potts, 2008). As discussed by Adriansen and Madsen (2009), there are both advantages and disadvantages when conducting research on the inside. Being an insider in relation to one's interviewees gives the advantage of having a shared history and a close knowledge of the context. The disadvantages concern power relations, positionality and presupposed shared understanding. Positionality, in particular, is negotiated - overtly or silently. Positions can become blurred when ownership and analytical power can be shared in the interview situation, as is the case in timeline interviews. In a study of the construction of knowledge in research communities (Madsen and Adriansen, 2006), we made qualitative interviews with our colleagues, but decided not to use timelines, paper or artefacts as we wanted to keep our position as researchers. This was already difficult when interviewing our colleagues, some of whom negotiated and challenged our analytical power.

\section{Discussion}

Using a timeline to guide one's interview can naturally be applied outside life history research. However, it only makes sense if time or chronology is important for the issue at hand. In my experience time is central more often that we realise. I have used the method for evaluating a development project at a department at a Danish university.

I was employed as a management consultant and in charge of the evaluation. It was clear that the project did not proceed as planned due to financial problems at the university at large and due to mergers within the faculty. An evaluation that did not take all these changes into account would show the project had failed. By using the timeline method, however, a more complex story unfolded. I made the interview with a group of five and used paper from a flipover. We were all sitting and standing around the paper and took turns in writing while trying to unfold what had happened to the development project (on one side of the timeline) in relation to the events at faculty and university levels. The group discussed how these outside events (on the other side of the timeline) had affected the project and during the interview their view of the project changed. From the outset, they felt that it had been a failure as they had not reached their milestones and targets. During the interview process, however, they came to a different understanding: the project had helped them navigate in a very turbulent period at the department. The project meetings had given them a place and a focus for something positive and productive, while the events at faculty and university level rendered them passive, negative and unproductive. In my understanding, using the timeline made them see the project 
in context with 'outside' events and to see these events in relation to each other over time. The group discussed and corrected each other until a shared understanding of the story and its chronology was constructed. Hence, the timeline in itself with the possibility to connect 'different worlds' was useful. A second important aspect was the use of the collective memory, the piece of paper where the participants took turns in writing and understanding the story. I found that this made them work towards an understanding themselves rather than I should 'lure' information out of them.

The timeline is supposed to help the researcher. It can help in a number of different ways. First, it can provide a chronological overview of a story. Second, the visual representation allows a number of stories to be told along the same line and provides space for multiple representations instead of a singular language. Thirdly, it can affect the interview situation in a positive way by engaging the interviewee in the interview process. Fourthly, it can assist an interviewee without a narrative packed and ready to be told. The timeline will not, however, help the researcher who is interested in the 'raw' narrative told with as little interference as possible.

One of the pertinent issues when doing life history research is that people often want to make sense of their lives. To use the words of Søren Kierkegaard "life is lived forward, but understood backward". This means that some interviewees may be very eager to make sense of events, to tell a nice, coherent story. Some researchers have criticised life history research exactly because life stories can become too neat and linear, full of purpose and meaning (see several examples of this critique in Petersen et al., 2007). One of the students also noticed this: "One would like to create meaning and coherence". For me, the problem is not life story interviews, but the way they may be used. We should acknowledge the strengths and limitations of the life story interview. It is an actor oriented perspective, where the researcher is interested in how the story is told, the type of events the interviewee picks and the way the interviewee makes sense of these events. However, the life story in itself may not tell us (enough) about the wider social, political, and environmental context (Steensen, 2007). Therefore, it can be wise to supplement life story interviews with other types of research.

A basis question in interview research is to which extent verbal language, which is serial, can represent the simultaneity of different feelings and emotions (Bar-On, 2006). The visual representation of the life story makes this dilemma less acute as there is space on the paper to give space to simultaneity, yet it does not solve the dilemma that humans have many experiences which cannot be intellectualised and expressed during a verbal interview (Prieur, 2002). This is, however, a dilemma shared by all research interviews.

\section{Concluding remarks}

The aim of this paper has been to explain and discuss timeline interviews as a method for doing life history research. My motivation for writing the paper was twofold: I wanted to share my positive experiences with this type of interview and I aimed at filling the gap in the existing literature.

Timeline interviews are not different from other qualitative interviews when it comes to problems and shortcomings. We still struggle to know to what extent the life story represents the lived life. Also, it is important to remember that the timeline interview is a snapshot in time. The interviewees will (hopefully) have new futures which may change their interpretation of their life history. This is not a problem of validity of the result of interviews, it is a condition. And time is important not only for life history research, but for many types of research. Studies 
of development, structural change, and novelty for instance all have a temporal dimension which should be part of the study.

When it comes to making qualified life story interviews, I find that the timeline method can be a useful tool. The method allows the interviewee to participate in the reporting of the interview which may give rise to ownership and sharing of the analytical power in the interview situation. Exactly for this reason, it may not be the most appropriate method for interviewing elites or for conducting insider interviews where positionality can be at play. The use of the timeline should not lead the interviewer or the interviewee to assume linearity and coherence; it is an organising principle for the events. It provides an opportunity for linking the story with the wider social, political and environmental context during the interview. While the method is very suitable for life story research, it can also be used for other types of studies where interviews are made.

\section{References}

Adriansen, H.K. (2002). A Fulani without cattle is like a woman without jewellery: a study of pastoralists in Ferlo, Senegal. Geographica Hafniensia, A11, Copenhagen

Adriansen, H.K. (2008). Understanding pastoral mobility: the case of Senegalese Fulani. The Geographical Journal 174 (3): 207-222

Adriansen, H.K. (2010). How criticality affects students' creativity. In C. Nygaard and C. Holtham (eds.) Teaching Creativity - Creativity in Teaching, pp. 65-84. Libri Publishing, Faringdon

Adriansen, H.K. \& L.M. Madsen (2009). Studying the making of geographical knowledge: The implications of insider interviews. Norsk Geografisk Tidsskrift - Norwegian Journal of Geography 63 (3): 145-153

Bar-On, D. (2006). Tell your life story: Creating dialogue among Jews, Germans, Israelis and Palestinians. Central European University Press, Budapest

Bergson, H. (1915.) Den skabende udvikling. Gads Forlag, København

Bergson, H. (1917). Det umiddelbare i bevidstheden: En studie over det umiddelbart givne i de sjælelige virksomheder og tilstande. Gads Forlag, København

Brown, R.A.; E.S. Burgress, S.D. Sales, D.M. Evans \& I.W. Miller (1998). Reliability and validity of a smoking timeline follow-back interview. Psychology of Addictive Behaviour 12 (2): 101-112

Boundas, C.V. (1993). The Deleuze reader. Columbia University Press, New York

Callewaert, S. (2007). Kritiske refleksioner over den livshistoriske trend. In Petersen, A.K., S. Glasdam \& V. Lorentzen (eds.) Livshistorieforskning og kvalitative interviews. Forlaget PUC, Viborg

Carey, K.B. (1997). Reliability and validity of the time-line follow-back interview among psychiatric outpatients: a preliminary report. Psychology of Addictive Behaviour 11 (1): 26-33 
Cross, N. \& R. Barker (eds.) (1994). At the desert's edge: oral histories from the Sahel. Panos/SOS Sahel, Glasgow

Goodson, I. (2010). Key note presentation at 3:e konferensen om Livsberättelseforskning, 25-26 November, 2010 at Karlstad University

Goodson, I. \& P. Sikes (2001). Life history research in educational settings: learning from lives. Open University Press, Buckingham

Hviid, P. (2008). "Next year we are small, right?": Different times in children's development. European Journal of Psychology of Education 2 (23): 183-198

Kvale, S. (1996). InterViews - an introduction to qualitative research interviewing. Sage Publications, Thousand Oaks

Madsen, L.M. \& H.K. Adriansen (2004). Understanding the use of rural space: the need for multi-methods. Journal of Rural Studies 20 (4): 485-497

Madsen, L.M. \& H.K. Adriansen (2006). Knowledge constructions in research communities: The example of agri-rural research in Denmark. Journal of Rural Studies 22 (4): 456-468

Mikkelsen, B. (1995). Methods for development work and research: a guide for practitioners. Sage, New Delhi

Petersen, A.K., S. Glasdam \& V. Lorentzen (eds.) (2007). Livshistorieforskning og kvalitative interviews. Forlaget PUC, Viborg

Plummer, K. (2005). Documents of life 2: an invitation to critical humanism. Sage Publications, Tyne \& Wear

Prieur, A. (2002). At sætte sig I en andens sted. En discussion af nærhed, afstand og feltarbejde. In M. Hviid. Jacobsen, S. Kristiansen \& A. Prieur (eds.): Liv, fortællinger og tekst. Strejftog i kvalitativ sociologi, pp. 135-155. Aalborg Universitetsforlag, Viborg

Rose, G. (1997). Situating knowledges: positionality, reflexivities and other tactics. Progress in Human Geography (21): 305-320

Rosenthal, G. (1993). Reconstruction of life stories: principles of selection in generating stories for narrative biographical interviews. In R. Josselson \& A. Lieblich (eds): The narrative study of lives, vol. 1, pp. 59-91. Sage Publications, New York

Scharmer, C.O. (2007). Theory U: leading from the future as it emerges. SOL, Society for Organisational Learning, Cambridge Massachusetts

Sikes, P. \& P. Potts (eds.) (2008). Researching education from the inside: Investigations from within. Routledge, Oxon 
Steensen, J. (2007). Biografiske interviews i et kritiske realistisk perspektiv. In Petersen, A.K., S. Glasdam \& V. Lorentzen (eds.) Livshistorieforskning og kvalitative interviews. Forlaget PUC Viborg

Thomas, W. \& F. Znaniechi (1918-1920). The Polish peasant in Europe and America. University of Chicago Press, Chicago

Winnicott, D.W. (1988). Babies and Their Mothers. Addison-Wesley, Reading, MA

\section{Author}

Hanne Kirstine Adriansen is an associate professor at the Department of Education, Aarhus University. Email: hkoa@dpu.dk 